\title{
Cement Mortar Properties Contain Crumb Rubber Treated with
} Alkaline Materials

Dr. Aziz Ibrahim Abdulla (Corresponding author)

Assistant Professor/Civil Engineering Dept., Tikrit University, Iraq

Tel: 964-770-845-0730Ｅ-mail: lan914@gmail.com

\author{
Wisam Amer Aules \\ Assistant Lecturer/Environment Engineering Dept., Tikrit University, Iraq \\ E-mail: wisamaamir@yahoo.com \\ Salwa Hadi Ahmed \\ Assistant Lecturer/Environment Engineering Dept., Tikrit University, Iraq \\ E-mail: env salwa99@yahoo.com
}

\begin{abstract}
In the present work, the properties of rubberize cement mortar are treated with alkaline materials and tested and compared with normal rubberize and normal cement mortar. The rubber, which is treated with different alkaline materials such as: $(\mathrm{NaOH}, \mathrm{NaOCL}$, and Commercial detergent powder) of high $\mathrm{pH}$ (13-14), is used as partial replacement for sand in cement mortar. The percent of replacement ranged from 15 to $35 \%$. Compressive strength, flexural strength, and modulus of elasticity are also tested for rubberize cement mortar, rubberize cement mortar treated with alkaline materials, and normal cement mortar. The results show that the treatment of rubber with alkaline materials significantly improves the properties of cement mortar. Moreover the results also show that $\mathrm{NaOCL}$ gives better improvement more than $\mathrm{NaOH}$, while commercial detergent powder shows negative effects on all cement mortar properties.
\end{abstract}

Keywords: Crumb Rubber, Mortar, High-Range Water Reducers, Alkalis, Compressive Strength

\section{Introduction}

The growing problem of waste tire disposal can be alleviated if new recycling routes can be found for the surplus tires. One of the largest potential routes is in construction, but usage of waste tires in civil engineering is currently very low (Cairns R, 2004). The processing of crumb rubber from waste tires produces steel and fiber by-product streams that, in many cases in California, must be disposed of due to the lack of market demand. The cost of disposing these materials raises the cost of processing and lowers the profitability of waste tire recycling. Thus, the recycling of waste tires could benefit from development of markets and increased demand for tire-derived steel and fiber (Integrated waste management Board, 2003).

The workability and mechanical properties of mortar containing shredded automobile and truck tires were evaluated by Raghavan, D. et al. (Raghavan D., 1998). They show that the addition of rubber particles resulted in a reduction of flexural strengths of the mortar mixes. The decrease in strength was dependent on the content of rubber granules or shreds and the shape of the shredded rubber. Preliminary results appear to show that the addition of rubber shreds to mortar reduces the severity of the plastic shrinkage cracking compared with the control mortar.

Some papers presented partial results of the mechanical behavior of the concrete filled with small volumetric fractions of crumbed tire rubber (also called rubberized concrete) (Topc'u I.B., 1997; Khatib Z.K., 1999; Segre N., 2000), but few of them contained dynamic experimental results. Some dynamic results with different volume fractions of fiber and rubber, frequencies and temperatures were studied by Herna' ndez-Olivares, F. et al. (Herna'ndez-Olivaresa F., 2002). The results of the dynamic tests were used to calculate the complex modulus and the capacity of this material to dissipate elastic energy due to low-frequency dynamic actions.

Segre and Joekes (Segre N., 2000) used surface-treated rubber aggregates with saturated sodium hydroxide $(\mathrm{NaOH})$ aqueous solution for 20 minutes at room temperature. Abrasion resistance experiments were performed with test specimens containing plain rubber aggregate or $\mathrm{NaOH}$-treated rubber. The results showed that the mass loss of specimens containing $\mathrm{NaOH}$-treated rubber was significantly lower than that of the specimens containing plain rubber aggregate. They stated that these results showed the increased adhesion obtained by treatment of the 
rubber aggregate.

Segre et al. (Segre N., 2003) showed that the small rubber particles (less than $300 \mu$ ) could improved some of mortar properties even when used in high proportion if the rubber treated with $\mathrm{NaOH}$. Also the additions of $10 \%$ $\mathrm{NaOH}$-treated tire rubber particles in mortar reduce the water sorption significantly, and enhanced the resistance to acid attach.

Güneyisi et al. (Güneyisi E., 2004) studied that the properties of rubberized concretes containing silica fume. They showed that the addition of silica fume into the matrix improved the mechanical properties of the rubberized concretes and diminished the rate of strength loss. Results also revealed that a rubber content of as high as $25 \%$ by total aggregate volume might be practically used to produce rubberized concrete with compressive strength of 16-32 $\mathrm{MPa}$.

Azmi and others (Azmi N. J., 2008) studied the mechanical properties of rubberized concretes. A control Portland cement concrete mix (PCC) was designed using American Concrete Institute mix design methods and crumb rubber contents of $10,15,20$ and $30 \%$ by volume were chosen by partially replacing the fine aggregate with crumb rubber. Totally 15 concrete mixes with three different water cement ratio $(0.41,0.57$ and 0.68$)$ were cast and tested for compressive strength, splitting tensile strength, flexural strength, and modulus elasticity. The results revealed that there was a reduction in strength for crumb rubber mixture, while slump values increase as the crumb rubber content increased from $0 \%$ to $30 \%$. These results indicated that crumb rubber mixture was more workable as compared to normal concrete and can be acceptable to produce crumb rubber concretes. The results also indicated that inclusion crumb rubber in concrete reduced the static modulus elasticity. Although there was a reduction in modulus elasticity, the deformability of crumb rubber concrete increased as compared with normal concrete

Topcu and Turhan (Topcu I. B., 2009) studied the properties of fresh and hardened rubberized self compacting concrete (RSCC). Rubber replaced aggregates at the contents of 60,120 and $180 \mathrm{~kg} / \mathrm{m}^{3}$ in self compacting concrete (SCC) by weight. They showed that the increasing in rubber content leads to increase in fresh properties and decreasing in the hardened properties such as compressive strength and durability. However, the different viscosity agents can provide appropriate results for RSCC containing the same rubber aggregate content and the hardened properties of RSCC are better than the properties of ordinary concrete even if they are lower than the ones of SCC.

Al-Mutairi and others (Al-Mutairi N., 2010) studied the effect of microsilica addition on compressive strength of rubberized concrete at elevated temperatures. An experimental investigation was carried out to study the effects of various percentages of fine/coarse tire waste and microsilica at various temperatures on the compressive strength of concrete. Generally, the use of microsilica or fine rubber mixed with microsilica as aggregate replacement of $5 \%$ by volume improved the compressive strength of concrete processed at a temperature of $150^{\circ} \mathrm{C}$. The addition of coarse rubber did not achieve any increasing in strength when it used as an aggregate replacement at any percentage. Moreover, the reductions in the compressive strength of concrete mixes at higher temperatures were much smaller for the fine rubber with $5 \%$ microsilica than those for control and coarse rubber mixes.

The problem of tires waste is very important and increases continuously in all of Iraq cities. These waste are un degradable and cause many problems in the environment. Very limited researches, especially about the treatment of solid waste in Iraq. There are no official data about the quantity of tires in Iraq till now; so the estimation according to the population in Iraq is about 4 million tires in a year coming from private cars only. This number increases greatly if other types of tires involve such as truck tires.

Present work includes the reuse tires in the cement mortar. Crumb rubber of tires is treated with alkaline materials and used in Ordinary Portland Cement mortar. A volumetric ratio is 15,25 , and $35 \%$ by volume of fine aggregate are chosen as partially replacing of fine aggregate with crumb rubber. Three types of alkaline materials are used to treat the crumb rubber and study the effect of this treating on the mechanical properties of cement mortar. Cement mortar cubes of $5 \times 5 \times 5 \mathrm{~cm}$ are used to compute the compressive strength at 3,7 , and 28 days as shown in Fig.1. Prisms of $4 \times 4 \times 16 \mathrm{~cm}$ are used to compute flexural strength and modulus of elasticity at 28-days as shown in Fig.2.

\section{Experimental Works}

\subsection{Materials}

Cement:- Iraqi standard ordinary Portland cement produce by (UCC Cement Company).

Fine Aggregate:-Graded fine aggregate from Tuz city. 
Super plasticizer (SP):- Using High Range Water Reducing Admixture (HRWRA) Sikament®FFN.

Rubbers:- The crumb rubber used is granulator and having a 2-2.36 mm nominal maximum size.

Alkaline Solution :-

A-NaOH $\quad 0.1 \mathrm{M}, \mathrm{pH}=13.9$.

B- Sodium hypochlorite (Bleaching material) NaOCL $0.1 \mathrm{M}, \mathrm{pH}=12$.

C- Commercial detergent powder produce by Alwazir company for detergent (ingredients:- Active matter 15\% Mw (348) anionic, STPP, Sodium sulfate, Sodium Carbonate, Sodium Silicate, CMC, Perfume, Optical Brightener, $\mathrm{pH}=13.8$ ).

\subsection{Treating}

Crumb rubber immersion in alkaline solution for $24 \mathrm{hr}$ and then washed to be used in cement mortar as saturated surface dry.

\subsection{Mixing}

The mixing ratio is 1:2.5:0.3:0.02 (cement: sand: W/C: SP/C). The volumetric percent of crumb rubber are $15 \%$, $25 \%$, and $35 \%$ as replacement of sand. The casting of cubes and prisms are made according to ASTM C109 and ASTM C348.

\section{Results and discussion}

\subsection{Compressive strength}

Fig.3. shows the compressive strength of rubberized cement mortars for different alkalinity treating. The rubberized cement mortar treated with $\mathrm{NaOCL}$ gives a compressive strength of 1.19 times that of normal cement mortar and of 1.8 times that of normal rubberize cement mortars.

This figure also shows that using $\mathrm{NaOH}$ as treating material will increase the compressive strength as compared with normal rubberize cement mortar and normal cement mortar. However, the treating by commercial detergent powder gives a slight increasing in compressive strength as compared with normal crumb rubber cement mortar, but it's still lower than normal cement mortar.

The improvement is due to the increasing of roughness of rubber due to treating by alkaline materials. This increase of roughness will lead to improve the adhesion force between rubbers and cement mortar. On the other hand, commercial detergent powder give negative effect due to producing foaming cement when reacting with cement and it is contain smoothen compounds that reduce the adhesion forces between rubber and cement mortar.

\subsection{Flexural Strength and Modulus of Elasticity}

The flexural strength of rubberize cement mortar is increased when using crumb rubber which is treated with $\mathrm{NaOCL}$ and $\mathrm{NaOH}$ as compared with normal cement mortar and decreased when using crumb rubber which is treated with commercial detergent powder as shown in Fig.4.

The modulus of elasticity is calculated by using flexural test results from the following Equation:-

$$
\mathrm{E}=\mathrm{PL}{ }^{3} \mathrm{C} /(48 \delta \mathrm{I})
$$

Where:-

$\mathrm{C}=\left[1+(2.4+1.5 \mathrm{v})(\mathrm{h} / \mathrm{L})^{2}-0.84(\mathrm{~h} / \mathrm{L})^{3}\right] ; \mathrm{P}$ :- load in the center of prism, $\mathrm{N} ; \mathrm{L}:-$ Span of prism, mm; $\delta$ :- deflection at centre of prism, $\mathrm{mm}$; I:- Moment of inertia, $\mathrm{mm}^{4}$; v:-Poisson's ratio; h:-height of prism, $\mathrm{mm}$.

Fig. 5 shows the effect of treating types on the modulus of elasticity. This figure shows that NaOCL gives significant increase in modulus of elasticity, while $\mathrm{NaOH}$ and commercial detergent powder decreasing the modulus of elasticity.

\subsection{Crumb Rubber Ratio Effect}

Increasing in crumb rubber ratio will decrease the compressive strength from $29 \mathrm{MPa}$ to $15 \mathrm{MPa}$ as shown in Fig. 6 for rubberize cement mortar which is treated with $\mathrm{NaOH}$. The other two alkaline materials give reduction as for $\mathrm{NaOH}$.

\section{Conclusions}

The treating of crumb rubber with alkalinity improves cement mortar properties and the following remarks can be shown from the experimental studies:- 
1) Treated crumb rubber with alkaline materials improved cement mortar properties (compressive strength, flexural strength, and modulus of elasticity).

2) Using crumb rubber treating with $\mathrm{NaOCL}$ increase compressive strength, flexural strength, and modulus of elasticity more than $\mathrm{NaOH}$, while using detergent powder gives negative effect.

3) The results show that using $\mathrm{NaOCL}$ gives better results than $\mathrm{NaOH}$ and commercial detergent powder.

4) Using of treated rubber will increase the early resistance of cement mortar as compared with normal rubberize cement mortar.

5) Using of treated rubber leads to increase the deformability and the load in flexural test increase and decrease before failure.

6) Using of rubber in cement mortar leads to fragmentary failure of the cement mortar in compression test, and the using of treated rubber will increase this fragmenting. Therefore using fiber is very importing to resist this phenomenon.

\section{Acknowledgement}

The authors wish to thank prof. Dr. Muzher Mahdi Al- Doury head of Environmental Engineering - Faculty of Engineering - University of Tikrit, for his great help. Also approbation and thanks are presented to engineer Haitham Nagy for his help in concrete laboratory.

\section{References}

Al-Mutairi, N., Al-Rukaibi, F., Bufarsan, A. (2010). Effect of Microsilica Addition on Compressive Strength of Rubberized Concrete at Elevated Temperatures. Journal of Mater Cycles Waste Manage, 12, 41-49.

ASTM C 109/C 109M. (2008). Test Method for Compressive Strength of Hydraulic Cement Mortars (Using 2in. or 50-mm Cube Specimens).

ASTM C348. (2008). Standard Test Method for Flexural Strength of Hydraulic-Cement Mortars.

Azmi, N. J., Mohammed, B. S, Al-Mattarneh, H. M. A. (2008). Engineering Properties of Concrete Containing Recycled Tire Rubber. ICCBT - B -, 34, 373-382.

Cairns, R., Kew, H. Y., Kenny, M. J. (2004). The Use of Recycled Rubber Tires in Concrete Construction. The university of strathclyde in Galscow, final report.

Güneyisi, E., Mehmet Gesog` lu, Turan O־ zturan. (2004). Properties of Rubberized Concretes Containing Silica fume. Cement and Concrete Research, 34, 2309-2317.

Herna'ndez-Olivaresa, F., Barluenga, G., Bollati, M., Witoszek, B. (2002). Static and Dynamic Behavior of Recycled Tire Rubber-filled Concrete. Cement and Concrete Research, 32, 1587-1596.

Integrated waste management Board. (2003). Assessment of Markets for Fiber and Steel Produced From Recycling Waste Tires. California State.

Khatib, Z.K., Bayom, F.M.Y. (1999). Rubberized Portland cement concrete. Journal of Mater. Civ. Eng., ASCE $11(3), 206-213$.

Raghavan, D., Huynh, H., Ferraris, C. F. (1998). Workability, Mechanical Properties, and Chemical Stability of a Recycled Tire Rubber-filled Cementitious Composite. Journal of Materials Science, 33, 1745-1752.

Segre, N., Alexandre, D., Galves, José A. Rodrigues, Paulo J. M., Onteiro and Inés Joekes. (2003). Use of Tire Rubber Particles in Slag Modified Cement Mortars. Proceedings of the 11th International Congress on the Chemistry of Cement, ICCC.

Segre, N., Joekes, I. (2000). Use of Tire Rubber Particles as Addition to Concrete Paste. Cement and concrete Research, 30, 1421-1425.

Topc,u, I.B. (1997). Collision Behavior of Rubberize Concrete. Cement and Concrete Research, 27(12), 1893-1898.

Topc,u, I.B. (1997). Assessment of the Brittleness Index of Rubberize Concrete. Cement and Concrete Research, $27(2), 1135-1139$.

Topc,u, I.B. (1997). Analysis of Rubberize Concrete as a Composite Material. Cement and Concrete Research, $27(8), 177-183$.

Topc, u, I.B., Bilir, T. (2009). Experimental investigation of some fresh and hardened properties of rubberized self-compacting concrete. Materials and Design, 30, 3056-3065. 

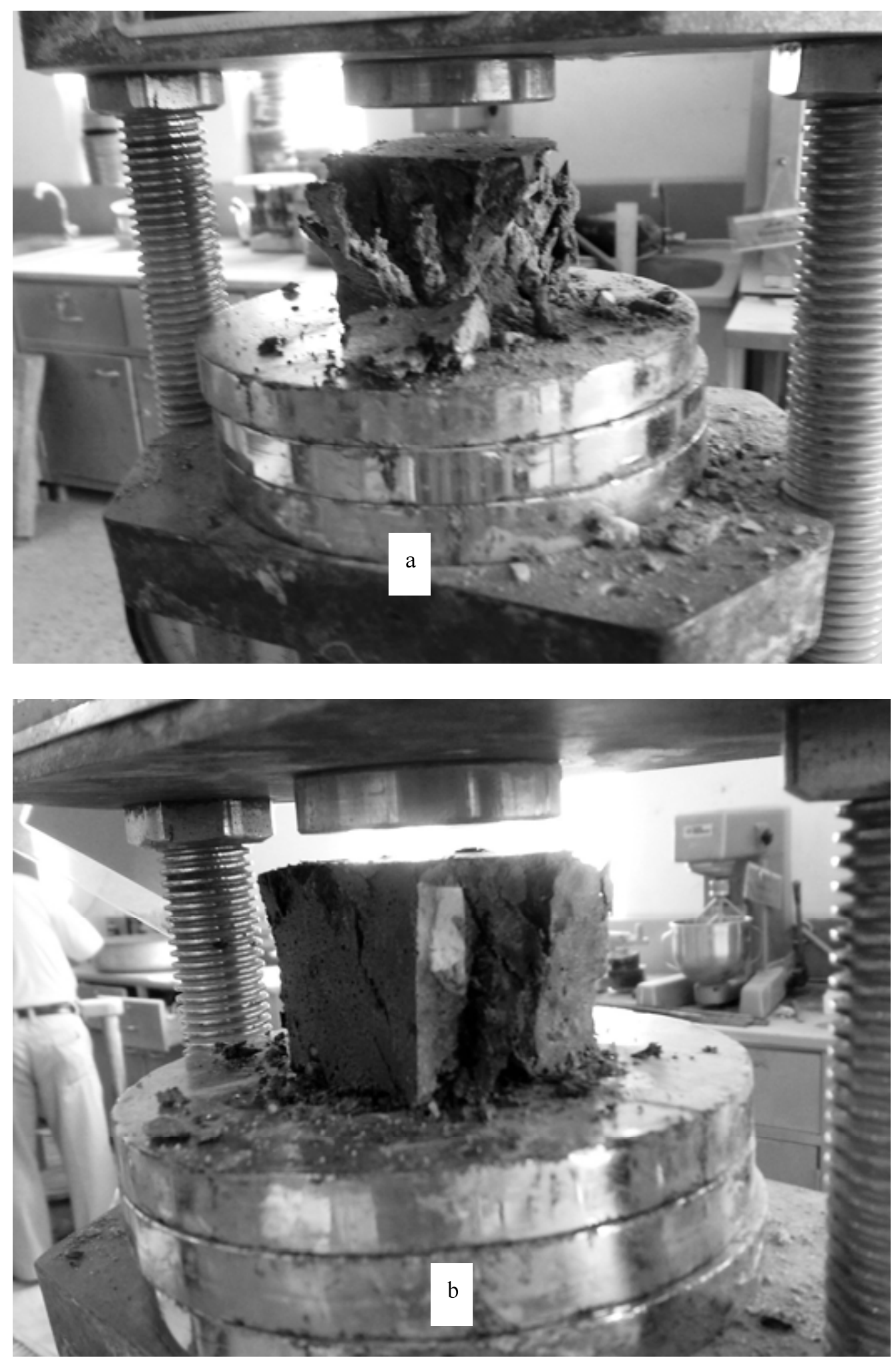

Figure 1. Compression test for (a) Rubber treated with NaOCL (b) Rubber treated with $\mathrm{NaOH}$ 

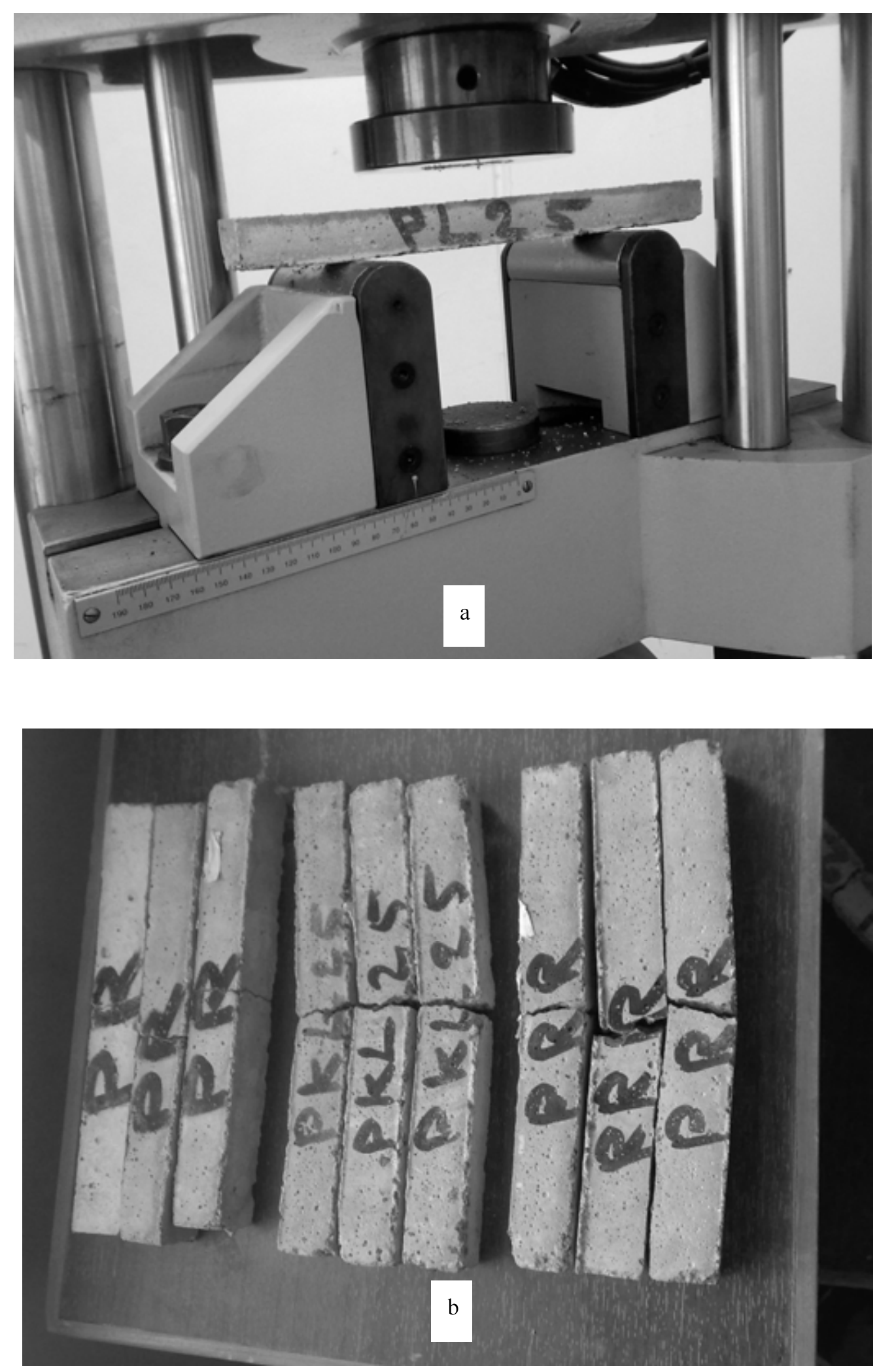

Figure 2. Flexural test (a) The prism before test (b) the prisms after test 


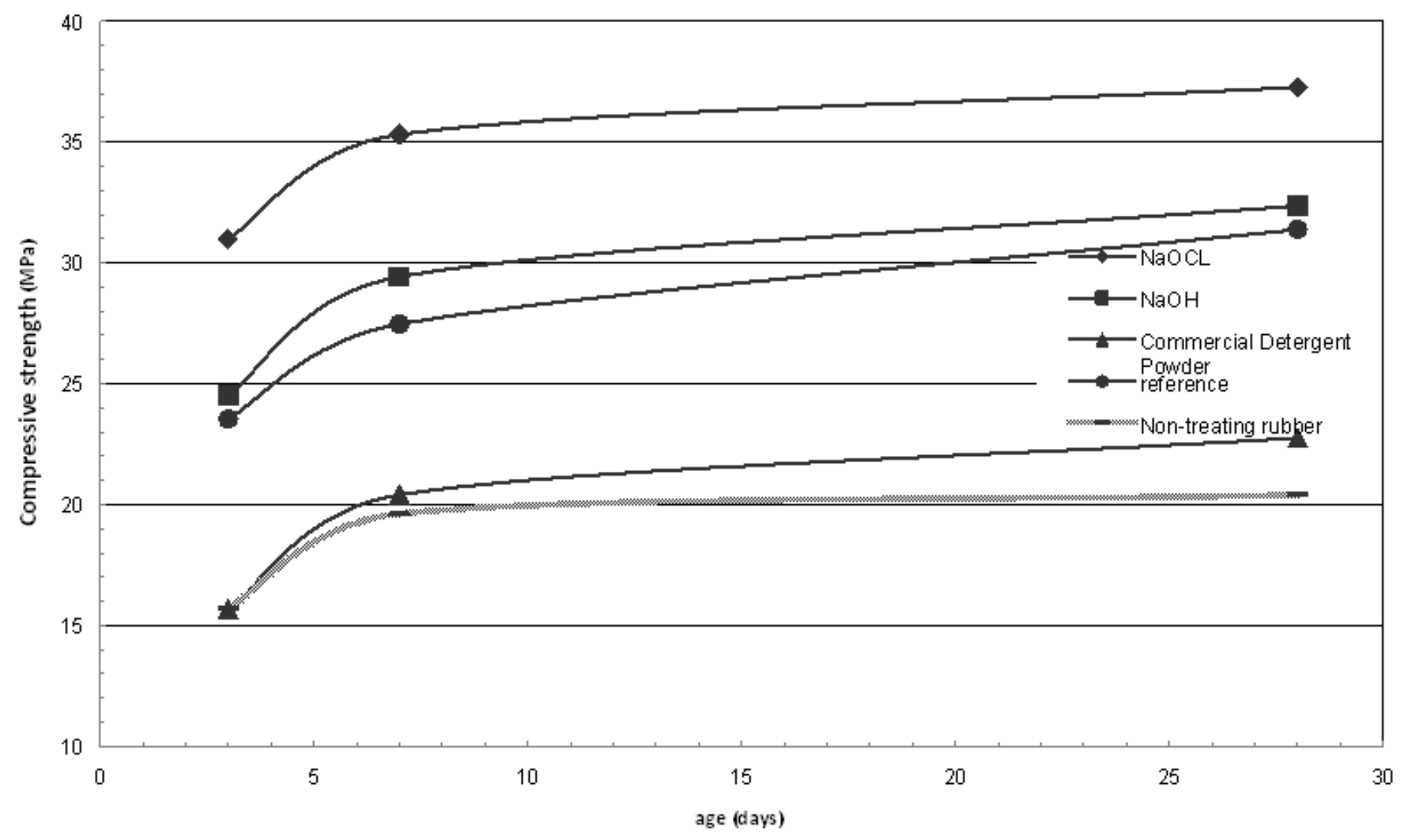

Figure 3. Compressive strength of rubberized cement mortars for different alkalinity treating

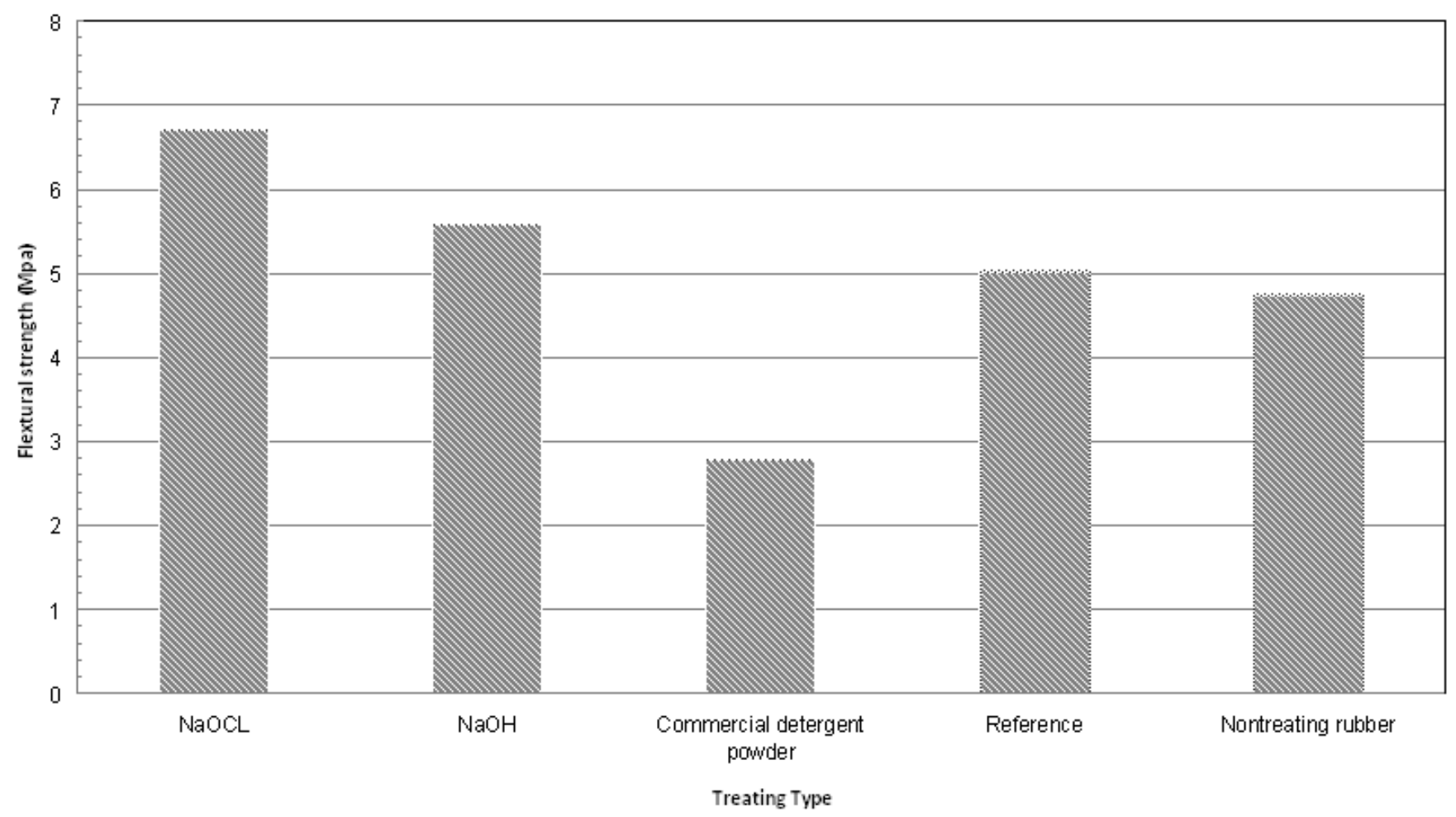

Figure 4. Flexural strength of rubberized cement mortars for different alkalinity treating 


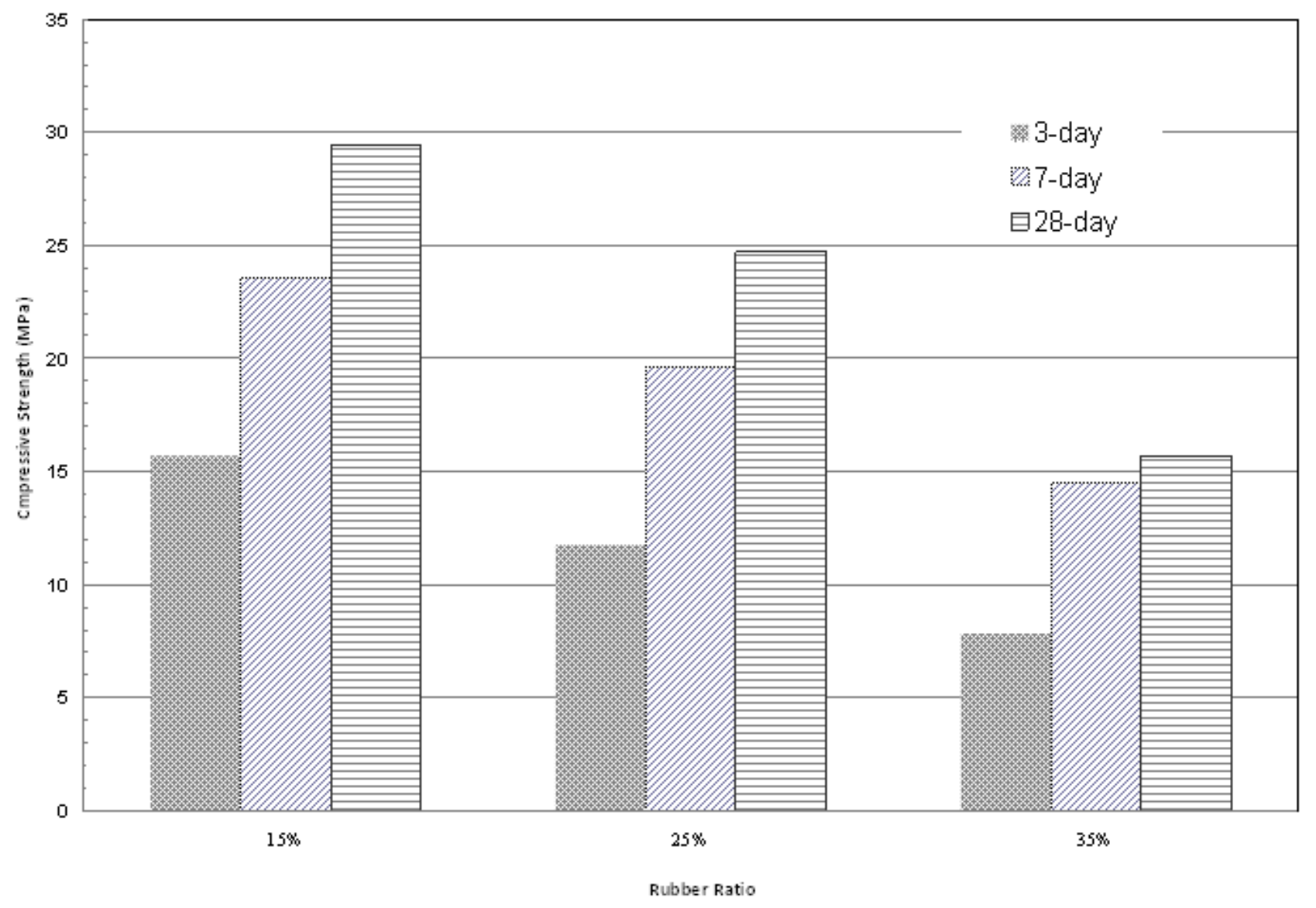

Figure 5. Effect of rubber ratio to the compressive strength

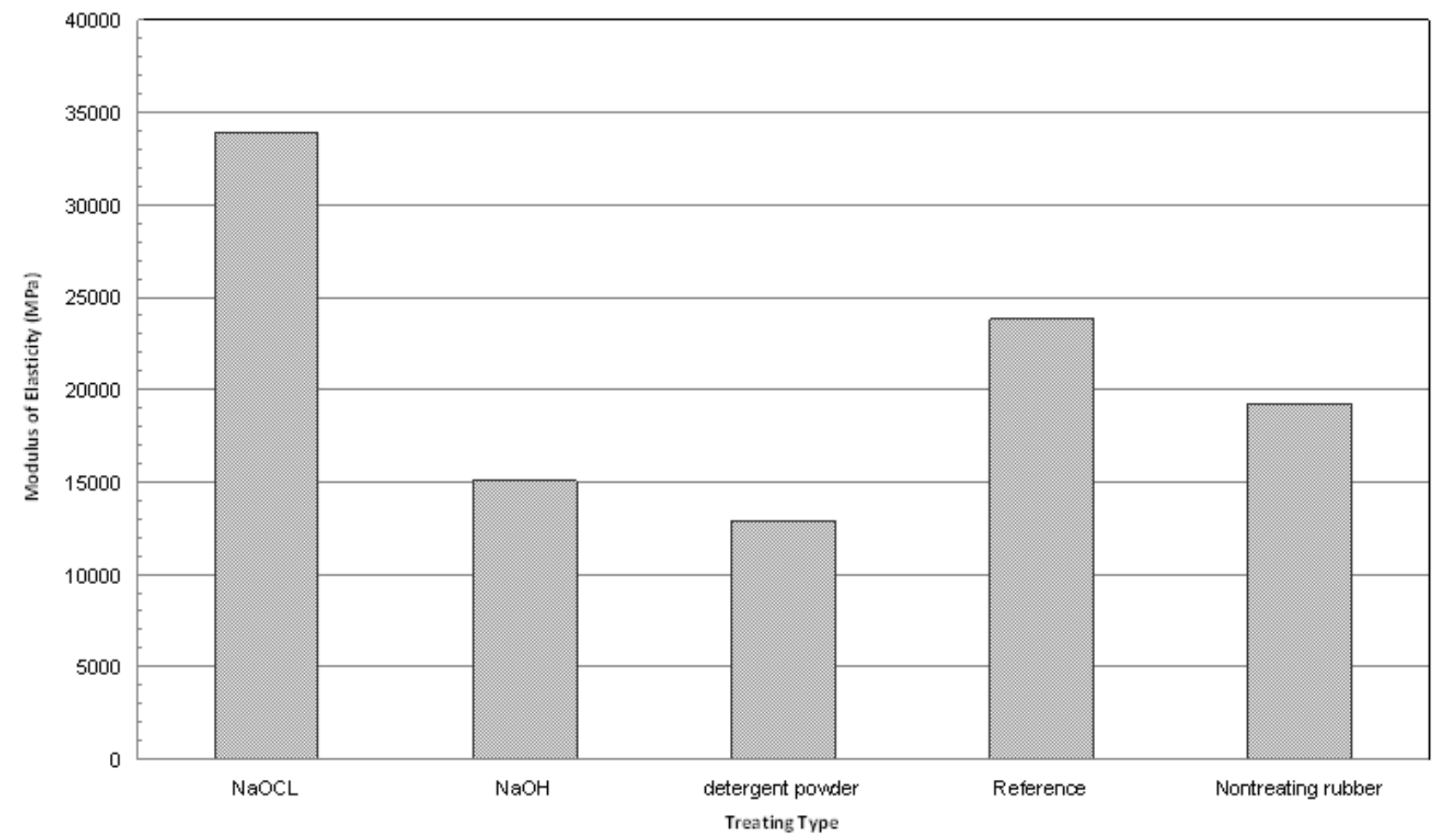

Figure 6. Effect of treating type to the modulus of elasticity 